\title{
Russian Approach to the Problem of Correlation of Linguistic Consciousness and National State of Mind
}

Tatiana Ivanovna Kobiakova

Nina Leonidovna Suntsova

\author{
Ziliya Mukhametianovna Raemguzhina
}

Anna Stanislavovna Tumanova

Ufa State University of Economics and Service, Russia, 450078, Ufa, Chernyshevsky Street, 145

Flyuza Gabdullinovna Fatkullina

Bashkir State University, Russia, 450076, Ufa, Zaki Validi Street, 32

\section{Doi:10.5901/mjss.2015.v6n6s2p111}

\section{Abstract}

Language as a bearer of the people's sociocultural memory is the basis of the nation's world perception. Linguistic view of the world - a number of micro and macrocosms reflecting the results of cognitive activity of a human being as a representative of the linguocultural community or ethnic group - is constructed through linguistic means, including lexical ones. Linguistic view of the world also creates the basis of the linguistic consciousness of the personality and national state of mind. This article investigates the problem of the language and thinking interaction in the context of cultural linguistics, an area of the Russian linguistics that emerged on the cusp of the XX-XXI centuries, and language education which basic task under the conditions of humanization of the Russian education is to form a linguistic identity. This work states the Russian scholars' opinion and author's interpretation related to this problem.

Keywords: linguistic consciousness, state of mind, mindset, stereotype of thinking, concept, sphere of concepts (conceptual domain), linguistic view of the world.

\section{Introduction}

Under the conditions of international communications and entrance of Russia to the unified world multicultural space, the question of language, culture and personality remains urgent. Its importance is proved by numerous researches made both by foreign and native scholars.

In linguistics, the ability of the language to model a view of the world that reflects peculiarities of the ethnic world perception and linguistic mindset of the personality in the person's consciousness is stipulated by the theory of W. von Humboldt about the internal form of the word, theory of linguistic relativity of E. Sapir and B. Whorf, theory of neohumboldtians (the founder of this school L. Weisberger introduced the notion of "the linguistic view of the world"), theory about internal content of the word as a sign that reflects cultural content and as a part of the language (N.G. Komlev).

The problem of the interaction of the linguistic consciousness and national state of mind is solved by efforts of various disciplinary directions of linguistics that study various forms of the culture expression in the language and personality as their center.

So, ethnolinguistics (Vezhbitskaya et al, 1996) researches only those lexical items that help to reconstruct either ethnic territory or material and intellectual culture of the ethnos.

Ethnopsycholinguistics (Sapir, 1993; Ufimtseva, 2000) regards a language as a tool of mental ordering of the world, including cultural values and means of assigning ethnic worldview.

Cognitive linguistics (Lakoff G., 1987) defines three basic problems related to studying the interaction of the language, culture and personality. They include nature of the linguistic knowledge, its digestion and use. The center of its attention includes concepts as frames of the consciousness that help to categorize and conceptualize the world.

Linguistic and cultural studies (Vereshchagin, Kostomarov, 1980) researches lexical items which level of 
conceptual content reflects peculiarities of the national culture expressed in the system of the language as non-equivalent and cultural and connotative vocabulary.

Cultural linguistics (Vorobiov, 1997; Stepanov et al, 1997) studies verbalized concepts of the culture which reflect the peculiarities of national and individual worldview in the consciousness of the linguistic identity.

Intercultural communication (Ter-Minasova et al, 2000; Noskova \& Romanova, 2014), which studies problems of interlinguistic communication, developed at the confluence of linguistic and cultural studies and cultural linguistics.

In the linguo-didactic aspect the interrelated study of the language and culture found expression in the linguoculturological concept of language teaching (Sayakhova, 2003). It proceeds from understanding the language as an informational code that serves as the basis of the knowledge about the world, language capacity of the person, cultural and historical environment, and historical memory that forms the linguistic identity.

This article is a linguoculturological research of the interaction of the language and thinking made for the didactic purposes. The academic novelty lies in the attempt to create a system description of this problem based on scientific works of Russian scholars. Besides, the article introduces the "Spirituality" conceptual domain that we structured. It holds a special place in the Russian linguistic view of the world as it is a system notion of the scale of spiritual and intellectual values of the Russian state of mind.

The research set the following goals: 1) to reveal the interaction of the language and thinking within the linguoculturological concept of the language teaching by describing key words of cultural linguistics, 2) to structure the "Spirituality" conceptual domain as the basis of the national state of mind.

These goals were achieved by reviewing scientific literature on the defined problem. It helped to show the system idea of Russian scholars about the interaction of the language and thinking, to structure the "Spirituality" sphere of concepts of the Russian linguistic view of the world, and to define its function in the Russian national state of mind.

\section{Methodology}

Methodological procedures of the research included the following:

Firstly, the method of descriptive analysis that includes careful selection of literature on the problem defined in the research and its study for determining general and particular regularities of linguistic and extralinguistic factors. In particular, we analyzed scientific resources (monographs, scientific articles, study guides, dictionaries) in order to reveal similarities and differences of the author's interpretation of key words that unfold the interaction of the language, culture and personality.

Secondly, the introspective method that is the basis of the principle of free material explanation being the main way of stating information expressed in scientific works of Russian scholars.

Thirdly, the combination of diachronic, synchronic and typological methods that allowed to compare various scientific opinions on this problem that are fixed in the contemporary Russian science and reveal general regularities in the explanation of the interaction of the language and thinking.

Fourthly, the modelling method that is an important component of the deductive approach to the language and assumes logical and notional composition of the language pattern. It helped us to construct the "Spirituality" conceptual domain related to determining and referring the conceptual sphere to the means of its expression in the language and the Russian state of mind. Theoretical grounding of modelling this linguoculturological space defined by the general theme and represented in the consciousness of the linguistic identity with the aid of concept words connected by associative, syntagmatic and paradigmatic relations was the idea of V.V. Vorobiov. He thinks that the correlation of lexical units with the nucleus of the linguoculturological domain can be represented as a functional relation that expresses specific dependence of one variable on the other: $Y=F(X)$, where $F$ expresses a regularity where a definite functional dependence is established between $\mathrm{Y}$ and $\mathrm{F}$ as a function value and argument (independent variable) (Vorobiov, 1997, p. 106-111).

Fifthly, the field method that reflects the peculiarities of interrelations between concept words and extralinguistic reality and intending the segmentation of the linguocultural space as a conceptual universal into thematic, semantic groups which titles express general themes and situations for concept words included in the "Spirituality" conceptual domain.

Sixthly, the introspective and association method that helped the authors of the research (who are linguistic identities, native speakers of the Russian language) to select from Russian defining dictionaries concept words that form an ideographic structure of the "Spirituality" domain. 


\section{Results}

It was revealed within the research that the interrelation of the language, culture and personality is obvious for Russian scholars. It is expressed in peculiarities of the national self-consciousness of the linguistic identity and namely in its linguistic mindset forming the basis of national state of mind. Basic component of the linguistic mindset includes stereotypes of thinking that are concept words contributing to successful socialization of the linguistic identity.

Concept words within the language education are defined as didactic linguoculturological units that contribute to forming linguistic national consciousness (national and linguistic mindset) that is the acquisition of language as a national cultural phenomena reflecting originality of the national state of mind.

Linguistic view of the world - sphere of concepts - as the basis of the personality's linguistic consciousness and national state of mind is nothing but a relatively stable system consisting of a nucleus and periphery and reflecting ethnically, socially, historically and scientifically determined categories of the worldview of the ethnolinguocultural community, i.e. specificity of segmenting the world image in accordance with the national state of mind. The "Spirituality" sphere of concepts vividly reflects the interrelation of the language, culture and thinking which biding element is a personality.

In the linguistic view of the world, the "Spirituality" conceptual domain is related to the "Person" language pattern and is the basis of national state of mind as a system of worldviews influencing stereotypes of the personality's behavior. The "Spirituality" conceptual domain is a hierarchically-organized linguoculturological space of concept words included in it. In the consciousness of the linguistic identity these concept words reflect an axiological paradigm that is the basis of social relations. "Spirituality" conceptual domain is characterized by binarity (ability to extend boundaries due to multiplying constituents), asymmetry (center - periphery), and inhomogeneity. In addition, the "Spirituality" conceptual domain has characteristics of the association area that is an ontological reflection of the person's thought.

\section{Discussion}

\subsection{Linguistic Consciousness and National State of Mind}

Knowledge about cultural and material values accumulated by the nation in the process of its self-development makes the basis of the worldview of ethnic consciousness. Language as a structured semiotic system contributes to keeping these values and transferring them to next generations and participates in forming national state of mind and linguistic consciousness of the personality.

In scientific researches linguistic consciousness is interpreted as a combination of images transferred with linguistic means; they are means of forming, keeping and remaking language signs that help the person to enter the process of genesis cognition as a competent figure. W. von Humboldt was the first person to introduce this notion to the science. He thought the language in its interrelations to be a founding of people's linguistic consciousness (Humboldt, 1985, p. 396-397). Linguistic consciousness is a verbalized form of the social culture, including ethnic culture. It is the basis of notional (conceptual) knowledge and social experience accumulated as a result of cultural and historical development of the ethnic group. Being a part of cognitive thinking, it defines ways of segmenting the global image of the world by the personality, i.e. interpretation and objectification of knowledge about it (Alefirenko, 2013, Zalevskaya, 2000). Linguistic consciousness as a means of forming, keeping and remaking language signs fixing cognitive activity of a person and as a mechanism of its determination (Sorokin, Tarasov, Ufimtseva, 1982, p.5) does not only reflect cognitive consciousness of the personality but also defines his psychological mentality and mode of thought.

As a linguistic universal it reflects peculiarities of the conceptualization of sociocultural space by the nation as a whole and a linguistic identity, in particular. Such identity not only knows the national language as a system and can organize discourse line with its aid, but using linguistic means also can model the worldview stipulated by the specificity of national perception, and organize behavioral model according to stereotypes accepted as model in this linguoculturological community. Herewith, the notional knowledge is transformed to linguistic presuppositions that contain cultural and pragmatic meanings of linguistic units' semantics - verbalized constants of culture (concepts, ideas, and symbols). However, it does not necessarily mean that linguistic units are identical to notions because their semantic filling differs by notional correlation with the reality reflecting material and spiritual culture, lifestyle, conditions of natural and social environment. The way of the world conceptualization is stipulated by national and cultural perception of figures that underwent linguistics, verbal and cognitive, and modal and estimative understanding. Hence, linguistic consciousness is nothing more but "a result of linguosemiologic representation" (Alefirenko, 2005, p. 174) of national worldview which within this work we identify as national state of mind. 
Scholars understand the national state of mind as the genotype of culture based on stereotypes of the worldview and behavior of all representatives of the ethnolinguocultural community. As "psycho linguistic intellects of different-scale linguocultural communities" (Thorik, Fanian, 2006, p. 253), it is a stable unique structure of characteristic sociocultural peculiarities of a specific people, i.e. mechanisms of thinking while coding, decoding and interpreting the world image.

As a universal of individual and national linguo-cognitive consciousness, the national state of mind is expressed in ways of nominating, objectification, and semantization of lexical means. So, using lexical items Russian philosophers (N.A. Berdiaev, V.S. Soloviev and other) name basic features that as a whole reveal stereotypes of thinking mysteriousness of the Russian soul including liberty (daring, rebellion), searching for absolute good, tolerance, nationalism, humanity (mercy). Russian scholars call such dominating features of the Russian state of mind as communality, readiness, Orthodoxy, autocracy, national character, collectivism, nationality, tolerance (Vorobiov, 1997, p. 160, 170-173); czar-centralism (integration of czar and the world in common "We"), charity, inaction (Lurie, cit.: Stefanenko, 2003, p. 147-149); and pessimism transferring to optimism in extreme situations (Stefanenko, 2003, p. 150). A. Vezhbitskaya refers emotionality, irrationality, tendency to fatalism, resignation and obedience, love to morality to notions that reveal the Russian state of mind (Vezhbitskaya, 1996, p. 33-34). W. Schubart defines the dualism of the Russian character through such lexemes as cruelty, sentimentality, sensationism, ascetism, depravity and holiness (Schubart, 1997, p. 84), while C. Kluckhohn uses heartiness, dependence on strong social contacts, emotional instability, irrationality, strength, indiscipline, need to obey the government (Kluckhohn, cit.: Stefanenko, 2003).

The national state of mind as a psychic state of the personality that reflects the worldview of the nation as a whole is stipulated in the person's consciousness by stereotypes of national linguistic thinking.

The contemporary science studies the phenomena of stereotype in various areas: sociology, psychology, knowledge engineering, ethnography, linguistics, ethnolinguistics, ethnopsycholinguistics, and cultural linguistics. The majority of them regard consciousness stereotypes as definite ideas about the reality from viewpoint of ingenuous consciousness. In this case stereotypes act as special signs that represent mental images of the worldview and influence communicative behavior of people. Stereotypes are a determined minimized invariant of local association implemented in conversation and reflecting peculiarities of national world perception. They are specially valuable items of mental and lingual complex of the native speaker and culture bearer. Their use is defined by personal needs of the interaction with the reality subject. Being verbalized items of thinking, mental stereotypes correlate with ingenuous pictures of the word in the consciousness of a person as a native speaker and culture bearer and act as cumulative items. In the linguistic identity's consciousness they help to reflect unmotivated features of specific culture-specific concepts that are characteristic of either a specific linguocultural community or the mankind, as a whole. Nationally specific stereotypes hold specific place among them. On the one hand, they are stipulated by the unity of the material world, universals of human existence, and on the other hand, they reflect the psychology of people as a bearer of linguistic consciousness. Their principle feature is social and ethnic belonging and linguistic expression. Their combination makes mindset of a linguistic identity as a center of language and culture.

\subsection{Concept as a Cultural Linguistic Universal of the National State of Mind}

In the personality's consciousness the national state of mind is formed by mental facts that are a system of verbalized cultural codes of the lingo-cognitive base.

Russian scholars (Zalevskaya, 2000, Krasnyk, 2000) classify mental facts as frames of cognitive and linguistic consciousness as follows: 1) concepts knowledge, 2) ideas: precedent phenomena, bestiaries; social stereotypes of behavior. Concept is one of the key notions of this research. The necessity of terminologisation of the "concept" lexical item arouse as a result of the need in ethnocultural authorization of semantic items, their reference to the linguistic identity (Fatkullina, 2015, p. 239).

The term arouse in the interior of scholastic philosophy (Abelard, Johannes Saresberiensis and other). Initially it meant a special form of cognition existing as general notions and ideas. Today scholars interpret it differently: it is a basic cell of culture in the mental world of the linguistic identity (Stepanov, 1997); it is a product of the human thought (construction) that is characterized not only of linguistic but also universal consciousness (Telia, 1996); it is "a sort of algebraic expression of the meaning a person operate in his writing speech" (Lihachev, 1997, p. 6); it is a verbalized meaning of linguistic realizations that form a lexical-semantic paradigm, an item of collective consciousness distinguished by the ethnocultural specificity (Vorkachev, 2004, p. 51) and others. Analyzing these definitions, we can find a general regularity. The majority of linguists think that according to the nature of its formation a concept does not depend on the linguistic form of expression as it includes a verbalized image notion (culture-specific concept) and something that can be expressed by extralinguistic means. In other words, a concept is a result of the argumentation of linguistic and cognitive 
activity of a person performed under definite historical, culturological and pragmatic conditions.

From the point of view of language education, concepts are a set of universal culturologically marked verbalized items of cognitive consciousness that reflect peculiarities of the national state of mind. Didactic side of the concept is expressed in its ability to connect the sense of the culture-specific concept with the sign in the process of the world conceptualization and categorization. Herewith, on the one hand, the word is a language sign representing only a part of the concept, i.e. its objective and notional essence. On the other hand, it is a cultural and semantic universal that has a comprehensive structure organized as a prototype - inhomogeneously, from center to periphery. That's why it is possible to speak about important features of the concept, including idiomaticity, figurativeness, archetype, ethnical coloring, subjectivity (Kobiakova and Legotina, 2014). It is subjectivity that deserves special attention, as it is the feature that is a converging point of national and cultural meaning of the concept, its figurativeness and nomination (a way of individual understanding of something that is hidden in the ideographic structure). As the verbalized concept determines a paradigm of the interrelation of the form, reality and content, it can be regarded as an item of language teaching. In this case, concept is nothing more but a verbalized item maximum abstracted, specifically represented in the linguistic consciousness that underwent cognitive remaking (interpretation) and marked by the national and cultural markedness. It reflects the world perception of the linguistic identity in combination with all valence bonds. Studying concepts, a person cognizes the world, becomes familiar with national and universal culture and forms own worldview.

Concept as a stable linguo-cognitive formation and a phenomenon of culture includes notional and encyclopedic characteristics; figurative and metaphoric connotations and national and cultural component of the meaning that reveals ethnocultural specificity of the concept through objective, syntagmatic, paradigmatic relations that are known to all members of the linguocultural community. The structure of the concept semantic content is revealed through semantic categories and subcategories represented by separate lexical items. Herewith, the boundaries of the concept structural content can be extended or narrowed depending on the level of influence of cultural and historic environment where a specific ethnic group is developed. For example, it is possible to single out the following components in the structure of Faith concept referring to spirituality: 1) reality (one clearly determines for oneself in what or whom to believe: To proselyte means to break someone in one's commitments, With good faith and fidelity means to serve honestly); 2) multidimensionality of existence (faith is an element of not only individual but also social consciousness: Take on faith means to entirely believe without demanding proofs); 3) worthiness (faith together with such notions as love, hope, benefit, truth, beauty forms a system of spiritual valuables). A comprehensive semantic structure of the concept is explained by the etymology of the word that helped to verbalize it: the initial meaning is an oath, swear (in devotion, veracity), then trust, confidence.

Concept as a collection of definite knowledge is filled with empiric content. It is an intermediary between words and extralinguistic activity, culture and person. On the one hand, verbalized concepts are activators of the mindset and basic categories of the national state of mind. On the other hand, they are a condition for the linguistic identity to successfully enter the ethnoculture and international space.

Abstract names hold central place in the linguoculturological space. Their semantics straddles peculiarities and richness of axiological and cultural paradigm of the people that use the language. A lot of scholars write about the importance of key concepts of the national culture names (Sterney and Bykova, 2000; Chernenko, 1997). Based on key concepts that reveal ethnopsychology, an elite linguistic identity (writers, scholars, politicians) enriches the linguistic consciousness of all representatives of this culture as national language speakers. It animates the development of ethnic spirituality that is also the basis of the national state of mind and linguistic view of the world as a component of the linguistic consciousness of the personality.

\subsection{Sphere of Concepts as a Linguistic Model of the World Image}

Sphere of concepts is a linguistic view of the world expressed with the aid of concepts verbalized in the personality's consciousness. From the point of view of language education, sphere of concepts is referred to the thesaurus of the linguistic identity, i.e. its vocabulary. Consequently, in order to understand and study socio-cultural space, become its competent member, it is necessary to learn how to use a language as a tool of modelling the world image in the consciousness. Herewith, it is necessary to remember that such modelling is stipulated by both individual and national beginning, as the linguistic identity perceives the world in accordance with the personal experience and received knowledge, on the one hand, and through the prism of national understanding assigned in linguistic items, on the other hand.

In order to define the importance of the sphere of concepts in the national state of mind, it is rational to characterize such notions as world image, view of the world and detect their interrelation. 
The world image is an invariant reflection of the objective world in the person's mind that is mediated by objective meanings and relevant cognitive schemes (Leontiev, 2004, p. 125). It is a constantly changing paradigm of social relations focused in the personality's consciousness as a sphere of concepts whereby it defines the lifestyle, peculiarities of his behavior in the society. The essence of the national world image lies in sematic, typological and axiological aspects that reveal the aspiration of every people to divide the reality into two worlds - proper and strange. The national world image is reconstructed in the person's consciousness as a spatial-temporal model (network of coordinates). It includes, firstly, time, space and language; secondly, national character; and thirdly, the national state of mind (Gachev, 1988, p. 53).

The model of the national world image (view of the world) as a product of active spiritual and material activity of the person represented by cognitive structures is seen as a vertical and horizontal scheme of the world order organization and includes three basic forms: 1) real view of the world - the world of objects and phenomena, 2) notional image of the world - reflection of the real view of the world in the personality's consciousness as a result of cognitive activity, and 3) linguistic view of the world - a model of the world and phenomena perception fixed on the verbal level by the ethnic group in the process of its historical and cultural development.

The world image notion refers to the view of the world notion. However, it is not synonymic as the view of the world serves, above all, for describing facts and phenomena of the objective reality. It is a sort of a scheme of modelling in the consciousness of an individual of the world space.

The view of the world notion appeared at the end of the XIX - the beginning of the XX centuries to denote physical characteristic of the reality. However, at the present time it became a fundamental notion reflecting the idea of modern concept of the human being, specificity of his existence. The view of world as a sort of "construction of sensational and rational (logical) model of the reality" (Brutian, 2000, p. 55) reproduces the integral image of the world in the individual's consciousness within initial worldview settings. The view of the world is formed through two interrelated thinking operations: first of all, explication - objectification and understanding culture-specific concepts of the objective world; secondly, creation of a new world image by reflecting (consciousness reflection in a language) objects of the surrounding reality.

A lot of scholars follow the idea that there is a conceptual and linguistic view of the world. Conceptual view of the world is a secondary reflection of the reality. It is interpreted as "an ideal notion of the whole interrelation of intrinsic objects and processes that accordingly exist in the same comprehensive chain of interrelations in the world of notions (Kolshansky, 1990, p.18). This is a unique mechanism of correlating the reality (existing apart of the human knowledge and thinking) with the ideal view of the world that is a result of cognitive activity and is expressed through the association and verbalized chain of sense relations in the consciousness of a child, a mentally healthy person (or vice versa psychopath) or the humankind as a whole. According to the principle of linguistic complementarity, beyond the conceptual view of the world, there are periphery areas of the linguistic view of the world that are serve as a source of additional information about the world and form universal, invariant view in the person's consciousness, varying from language to language (Brutian, 2000, p. 58-59). The reflection of the reality in the person's consciousness is assigned as a cogitative world on the basis of the language.

Researchers (Raemguzhina, 2009, Hairullina, 2005) regard the linguistic view of the world notion as a result of linguistic conceptualization of worldview categories of the culture. Being a language pattern of the world image, the linguistic view of the world does not simply describe the organization of the existence but also establishes patterns of personal and national interpretation of the reality, i.e. it reflects national and cultural specificity of the outlook of both the person as a native speaker and ethnos as a whole. Basic feature of the linguistic view of the world lies in the peculiarities of forming a strategy, thinking stereotypes, life of the society as a whole and of a specific linguistic identity. We follow understanding of the linguistic view of the world as a model of the people's outlook through the language prism. In this case not only the world organization but also a combination of knowledge and ideas about it is described with the aid of language means. Accordingly, the linguistic view of the world is a model of structuring a system of knowledge and ideas about the reality of culture-specific concepts verbalized in a specific linguistics way.

Linguistic and conceptual views of the world are tightly interrelated with each other, i.e. in the state of continuous interrelation and go up the intrinsic view of the world. Herewith, interpreting the reality within a specific language, the linguistic view of the world reveals the content of conceptual view of the world and consequently is one of its most important elements.

National originality of the linguistic view of the world is expressed in the content-related part of the language, and in particular in ways of nomination and internal form of the word and phraseological unit, vocabulary with national and cultural component of the meaning. Herewith, the word acts both as a unit of language and a unit of culture, concept name. 
Lexical items verbalizing spiritual notions that are a foundational beginning of estimating the world and intrapersonal and social relations existing in it hold a special place in the national linguistic view of the world.

\subsection{Spiritual Aspect of the National State of Mind}

The mindset and the state of mind are not identical notions as it was stated above, the state of mind is a system of worldviews, and the mindset includes images and ideas that help the personality to define the strategy of his behavior, choose ways of modelling the world image and define his place in it as a representative of a specific ethnos. In other words, the mindset is a combination of mental models that in the person's consciousness represent, using linguistic means, the schemes of behavior in stereotype situations, intellectual habits expressed in individual and national interpretation of the reality.

We can agree with the opinion of scholars (Vorobiov and Sayahova, 2006) that the mindset is characterized by two forms of existence.

Firstly, linguistic mindset is correlated to socio-cultural linguistic presuppositions and expressed in linguistic means used by a person for reproducing the image of the world in his consciousness. For example, proverbs contain background knowledge that contains culturological information about culture-specific concepts of the reality that, being its part, reserved for a relevant key word with a concept name. On the one hand, proverbs identify cultural and national coloring. On the other hand, they are one of the ways of functional aspect of key words of concept names in the discourse of native speakers and culture bearers. Thus, in the Russian linguoculturological space it is admitted to say mean-spirited about the people who have no spiritual interests; if it is necessary to point at the person's self-control, self-possession, it is appropriate to use a phraseological unit presence of mind;Russian spirit proverb says about the spiritual essence of the Russian nation and others.

Secondly, the speech mindset is a way of individual interpretation of the macrocosm and reflection of its peculiarities in the socio-cultural discourse. For example, the intelligence notion as a result of the person's cognitive activity that acts as a real source of knowledge and, consequently, related to the personality's memory is differently understood by representatives of the Russian culture: it is "thinking that strives for a specific objective content" (Soloviov, 1998, p. 77, 81); it is the person's strive for understanding the real sense of the world by becoming familiar with Universal intelligence (Berdiaev, 2000, p. 69).

The mindset as the basis of national state of mind is adjacent to the personality's spiritual self-consciousness that helps him to orient in the constantly changing world and acts as a criterion of its estimation. Consequently, the role of "the language is not so much in transferring information as in internal organization of something that is to be informed, hereupon the space of meanings arise" (according to terminology of Leontiev A.N.), i.e. assigning knowledge about the world in the language where national and cultural experience of a specific linguistic community is interweaved. It is the content side of the language where the view of the world of a specific ethnos is revealed and which becomes the basis of all cultural stereotypes (Fatkullina, 2014).

Spirituality is a special feature of soul that appears in the domination of person's intellectual and moral interests over material ones.

The notion "spirituality" is especially important for a Russian person. It is related to the ideas of our ancestors about the spirit as the basis of one of the person's nature components. In the Russian mindset spirituality as well as spirit are abstract notions that reflect non-material state of soul. Spirituality contributes to the development of creative activity in a person and breaks in cultural heritage of the ethnos and world community as a whole by that.

Spirituality as a system of moral values is revealed in the texts of the Holy Bible, Holy Fathers' Legends (prephilosophy).

Thus, the Bible singles out basic universal values of the world creation realized with the aid of concepts that are verbalized in the following lexical items: love, truth, evil, beauty, world and others. We must mention that in the modern Russian language some of them lost their initial meaning. For example, the Guilt concept was initially identified with the notion of the first sin - a violation of the moral law as the God's commandment that is immediately followed by retribution. At the present time it is interpreted as a fault, misdeed. However, the language kept the stereotypes of national thinking that point at the relation to the Holy Bible (sin mixed up; out of ham's way; deadly sin and other).

We also find the development of spiritual aspect as a doctrine of the person's existence in the works of Old Russian literature. For example, "Morals of Vladimir Monomah" emphasizes such notions of spirituality as beauty, world, harmony of the world creation, love, sympathy, wit.

Such value as truth also defines a high level of spirituality of the society and person, its morality and social justice. "Russian search for truth is an internal spiritual dominant of the Russian national personality that defines its victories and 
defeats: God and good people stand for the truth, The one who keeps the truth is awarded by God, God is not in might but in right (that is what Aleksandr Nevsky said) (Vorobiov and other, 2014, p. 65).

Russian philosophers and scholars of the XIX - XX centuries see spirituality as the basis of the objective world and the most important dominant of cultural values. Much information about understanding spirituality in the Russian linguistic view of the world is contained in:

1) Monographs, for example, "Linguistic Conceptualization of the World (as Exemplified in Russian Grammar)" (Bulygina, Shmelev, 1997.) "Linguistic View of the World (Materials for Dictionary)" (Shmelev, 2002), "Happiness as Linguistic and Cultural Concept" (Vorkachev, 2004) and other scientific works,

2) Periodicals in philosophy and linguistics, for example, "Issues of Philosophy", "Logical Analysis of Language. Truth and Veracity in Culture and Language", "Russian at School", "Russian Speech", "Russian Abroad" and other periodicals,

3) Linguoculturological dictionaries, for example, "Constants. Dictionary of the Russian Culture" (Stepanov, 1997; additional edition 2001); "Concepts of Spirituality in the Russian Linguistic View of the World" (Kobiakova, 2004), "Russian Word - Russian World" (Sayahova et al, 2010) and other reference literature.

Spirituality defines the system of values that are not only normalizers of the socio-cultural space but also a mechanism of motivating the personality's activity. Its semantic content as of the culture constant is revealed by a combination of concepts verbalized in the consciousness of a personality with linguistic means, above all, lexical items that can be represented in various oppositions. Thus, in the Russian linguistic view of the word this is a dichotomy lightdarkness, proper-strange, good-evil,space-time. Concepts of spirituality names form a fragmentary part of the common linguistic view of the world that is a fundamental beginning of estimating the world and intrapersonal relations existing in it. That's why spirituality can be regarded as a nucleus of linguistic mindset that is the basis of national state of mind and linguistic consciousness.

\subsection{On the Question of Structuring the Conceptual Domain: "Spirituality" Sphere of Concepts in the Russian Linguistic Consciousness and the National State of Mind}

While structuring the "Spirituality" sphere of concepts as the basis of the Russian linguistic consciousness of the basic part of the Russian linguistic view of the world, we adhere to axiological aspect: in the Russian linguistic view of the world the "Spirituality" sphere of concepts is represented as an axiological paradigm.

In the Russian linguistic view of the world it is a hierarchal combination of linguistic units - stereotypes of the national state of mind of the Russian people. The domain under research has a dimensional structure as its components are not only linguistic units but also culture items - concepts that reflect the interrelation of the language and culture in the extralinguistic dimension. Elements of this domain (concepts, thematic, lexical groups, etc.) project the linguistic model of the spiritual world of the Russian people in the linguistic consciousness of the personality and thereby constitute a combination of items combined by a common linguistic meaning.

The "Spirituality" conceptual domain occupies the whole range of linguistic understanding of the personality's spiritual development and includes: 1) a nucleus expressed by the concept name "Spirituality" with a "Person" ideographic domain in the center organized by lexical and grammatical groups, and 2) periphery representing associations of the concept.

Since the "Spirituality" conceptual domain occupies the whole range of linguistic understanding of the personality's spiritual development, it provided us with the right to focus spirituality concepts around the "Person" central notion.

The "Person" ideographic domain is represented by syntagmatic (through the compatibility of concept words of the spiritual sphere of the Russian people) and paradigmatic relations of the Person is a Russian national personality ideographic domain: spirituality $=\mathrm{F}$ (internal world of the person); justice $=\mathrm{F}$ Rus. (world perception); love $=\mathrm{F}$ Rus. (feelings); guest = F Rus. (relations) and others.

It is proved that the main factor forming the language vocabulary is relations of the reality itself duly "refracted" in the language. That's why thematic principle of classification is based on the notion of the thematic group that is a combination of words being in semantic distance and representing components of material culture of a specific ethnic group. Thematic domain is a combination of words denoting notions of a specific subject area or the person's living environment (art, science, education, etc.). Meanings of words in a theme line are defined through the thematic dominant.

Thematic division of the "Person" ideographic domain was based on understanding the theme as a content of people's (native speakers') conceptual knowledge about objects and phenomena of the reality and rest on characteristics of the Russian state of mind: 1) religiosity (Beingness, Internal world and state of the person, World perception); 2) striving for the highest forms of experience (Intellect, World perception); 3) conciliarism (Feelings); 4) world kind- 
heartedness (Relations); and 5) greatheartedness (Person's skills and activity).

Polarization as one of the main characteristics of the Russian state of mind in the "Person" ideographic structure is represented as oppositions: light-darkness (for example, truth - reality - lie, good - evil and other concepts), spacetime (way - path - fate), proper - strange (motherland - home- hearth - family - guest, friend - enemy, friendship enmity and other).

Unlike thematic, semantic domain is a hierarchal structure of a variety of lexical units combined by an invariant meaning and reflecting a specific notional sphere in a language. Herewith, features of objects, processes, and phenomena comprehended through the prism of national and cultural self-consciousness correspond to the denomination meaning in the objective reality, while objects, processes and phenomena themselves correspond to the denomination subject in the objective reality.

Based on principles of structuring a semantic domain (Karaulov, 1976) and the idea that, firstly, the concept can be understood only on the basis of the whole combination of lexical items representing it; secondly, semantic domains formed by concept words fully represent relevant notional fragments of the cognitive view of the world and thereby provide the relativeness and combination of the cognitive and linguistic view of the world; thirdly, such domains undergo constant changes, advance and develop; we divided thematic fields into lexico-semantic ones. Vocabulary in them verbalizes abstract and presentational notions that according to the denomination theory simultaneously contain both the meaning and the subject in the significant and denotation. It is a combination of reflection of archisemes integrating meanings of general notions in the national state of mind. In particular, the home archiseme combines the following words that represent the spirituality concepts: Motherland, family, good, reality and others - and stereotypes of national thinking represented as proverbial and textual material - a specific layer of culture reconstructing the linguistic view of the world as image words. We singled out the following semantic domains: way - path - fate, life - death, custom, light darkness, intellect - with, God - belief - spirituality - soul - heart - memory, liberty - freedom - captivity, good - benefit evil, mercy - justice, beauty, hope, truth - reality - lie, motherland - home - hearth - family - guest, friend - enemy, friendship - enmity, peace - war, gift - talent - creativity - labor, guilt - conscience - shame, call - honor (=dignity), love - hatred - gladness - anxiety - happiness - sorrow. Concepts of spirituality name are brought out in the names of semantic domains. They represent a combination of norms, estimations and ways of the person's existence in the real world, for example, love, conscience, friendship and others, and objective culture-specific concepts like home, guest, enemy that lost their initial nomination and realize in the concept an image abstracted in this object, i.e. the denotative or figured and motivated aspect of the meaning of a specific concept is interpreted through the sign-oriented form. For example, in the Russian person's consciousness the name of the Home concept is associated, above all, with a family that is the ethic basis of the personality's life.

Thus, the "Spirituality" conceptual domain is a multidimensional combination of diversified linguistic units, subordinated one to another hierarchically, connected by a common theme (personality's spiritual development), and included as a system of values in the Russian linguistic view of the world that is the basis of the linguistic mindset and the national state of mind of the Russian linguistic identity.

\section{Conclusion}

Thus, at the present stage of the development of cultural linguistics and language education the question of interaction between the language, culture and personality remains urgent.

Based on the researches of Russian scholars, the research gives an analysis of key notions of cultural linguistics: image of the world, view of the world, linguistic view of the world, sphere of concepts, linguistic consciousness, the national state of mind, and determines their interrelation.

The notion of sphere of concepts is urgent for our research. Russian scholars understand it as a form of culture existence in the personality's linguistic consciousness.

Sphere of concepts as a relatively stable system that consists of a nucleus and periphery is a part of cognitive and linguistic consciousness. This is a linguoculturological paradigm that reflects national and individual including scientifically determined worldview of the linguistic identity as a national language speaker, hence a representative of the linguocultural community. The specificity of segmenting the linguistic view of the world by native speakers in accordance with the peculiarities of the national state of mind also reflects peculiarities of conceptualization of the world image in their consciousness.

"Spirituality" sphere of concepts plays a special role in didactic goals. It holds a specific place in the Russian common view of the world as it is a system of estimative relations in the Russian national state of mind. The "Spirituality" conceptual domain represented in the research occupies the whole range of linguistic understanding of spirituality by a 
Russian person and has 1) a nucleus expressed by the "Spirituality" concept name, 2) a center being a "Person" ideographic domain based on thematic groups of combined lexico-semantic areas of spirituality concept words, 3) periphery that is associations for the specific concept. This linguoculturological model can be used within the language education while forming linguoculturological competence of the linguistic identity.

The results of the represented research can be used for such disciplines (teaching such disciplines?) as "Intercultural Communications", "Russian as the Foreign Language", "Linguistic and Cultural Studies" and in educational lexicography.

\section{References}

Alefirenko, N.F. (2005). Disputable Issues of Semantics (pp. 326). Moscow: Gnosis.

Alefirenko, N.F. (2013). Cultural Linguistics: Axiological Space of the Language: study guide (pp. 288, $3^{\text {rd }}$ edition). Moscow: Flinta Science.

Berdyaev, N.A. (2001). Russian Idea. Basic Problems of the Russian thought of the XIX century and beginning of the XX century. Selfcognition (pp. 11-249.). Moscow: Expo-Press.

Brutian, G.A. (2000). Language and Worldview. Language and Culture. Specialty Course Reader for philologist students (Edited by Prof. Sayakhova, L.G., pp. 55-59.). Ufa: Periodical of the Bashkir University.

Bulygina, T.V., \& Shmelev, A.D. (1997). Language Conceptualization of the World (as Exemplified in the Russian Grammar) (pp. 576). Moscow: Languages of Russian Culture.

Gachev, G.D. (1998). National Characters of the World. Series of Lectures (pp. 432). Moscow: "Academia" Publishing Center.

Humboldt, W. (1985). Language and Philosophy of Culture. Moscow: Folio.

Vezhbitskaya, A. (1996). Language, Knowledge, Culture (393 p.). Moscow: Progress.

Vereshchagin, E.M., \& Kostomarov, V.G. (1980). Word Theory Based on Linguistic and Cultural Studies (pp. 320). Moscow: The Russian Language.

Vorkachev, S.G. (2004). Happiness as Linguistic-Cultural Concept (pp. 236). Moscow: Gnosis Publishing House.

Vorobiov, V.V. (1997). Cultural Linguistics (Theory and Methods): Monograph (pp. 331). Moscow: Publishing House of the Peoples' Friendship University of Russia.

Vorobiov, V.V., \& Sayakhova, L.G. (2006). The Russian Language in the Dialogue of Cultures: Study Guide (pp. 286). Moscow: Ladomir. Vorobiov, V.V., Suleymanova, A.K., Fatkullina, F.G., \& Khayrullina, R.H. (2014). Reflection of National Linguistic View of the World in Real Life of Bashkortostan: Monograph (pp. 208). Ufa: RIC of the Bashkir State University.

Zalevskaya, A.A. (2000). Introduction in Psycholinguistics (pp. 382). Moscow: Russian State University for the Humanities.

Karaulov, Yu.N. (1976). General and Russian Ideography (pp. 338). Moscow: Nauka.

Kobiakova, T.I. (2004). Concepts of Spirituality in the Russian Linguistic View of the World. Linguoculturological Dictionary (pp. 158, Edited by Prof. L.G. Sayakhova). Ufa: "Shtaim" LLC.

Kobiakova, T.I., \& Legotina, E.V. (2015). Concept as a Category of Ethno-linguocultural Consciousness of the Personality. Science and Education in the Life of the Contemporary Society: Proeedings of the International Research-to-practice Conference on December 30, 2014: in 12 books. Book 5 (pp. 63-67). Tambov: "Ucom Consulting Company" LLC.

Kolshanskiy, G.V. (1990). Objective Worldview in Knowledge and Language (pp. 108). Moscow: Nauka.

Kon, I.S. (1971). On the Problem of National Character. History and Psychology (pp. 122 - 158). Moscow: Nauka.

Lakoff, G., \& Johnson, M. (1987). Metaphors We Live By. Language and Modelling Social Interaction. Moscow: Progress.

Leontiev, A.A. (2004). Linguistic consciousness and World Image. Language and Speech in General and Pedagogic Psychology: Selected Works on Psychology (P. 123-140.). Moscow: Publishing House of the Psychological and Social Institute; Voronezh: Publishing House of "MODEK" SPA.

Likhachev, D.S. (1997). Sphere of Concepts of the Russian Language. Russian Philology. From Philology Theory to Text Structure. Anthology (pp. 280-287, Edited by Prof. Neroznak, V.P.). Moscow: Academia.

Raemguzhina, Z.M. (2009). Bashkir Anthroponymycon in Light of Linguistic View of the World. (Synopsis of thesis of Doctor of Philology), Bashkir State University, Ufa.

Sayakhova, L.G. (2003). Linguoculturological Concept of Teaching Russian // Russian Word in the World Culture. Proceedings of the X Congress of MAPRYAL. Saint-Petersburg, June 30 - July 5, 2003 Methodology of Language Teaching: Traditions and Perspectives. In 4 volumes. Vol. II Educational Space of the Russian Language as Foreign (Edited by Lubimova, N.A., Moskovkina, L.V., Rogozhina, N.O., \& Yurkov, E.E., pp. 408 - 412.). Saint-Petersburg: Polytechnic.

Sayakhova, L.G., Mullagalieva, L.K., \& Khasanova, D.M. (2010). Russian Word - Russian World. Linguoculturological Minimum Dictionary. UFA: RIC of the Bashkir State University.

Sapir, E. (1993). Selected Works on Linguistics and Cultorology. Moscow: Progress.

Sorokin, Yu.A., Tarasov, E.F., \& Ufimtseva, N.V. (1982). "Cultural Sign" of L.S. Vygotsky and Hypothesis of Sapir-Whorf. National and Cultural Specificity of the USSR Peoples' Communication (pp. 5 -12). Moscow: Nauka.

Soloviov, S.S. (1998). Spiritual Basics of Life. Selective Works. Rostov-on-Don: Fenicx.

Stepanov, Yu.S. (1997). Constants. Dictionary of the Russian Culture. Research Experience (pp. 824). Moscow: "Languages of the Russian Culture". 
Sternin, I.A., \& Bykova, G.V. (2000). Concepts and Lexical Gaps. Linguistic Consciousness: Forming and Functioning. Collection of articles (Editor-in chief N.V. Ufimtseva, pp. 55 - 68.). Moscow: Institute of linguistics.

Stefanenko, T.G. (2003). Ethnopsychology: Manual for higher educational establishments (3rd edition, corrected and supplemented, pp. 368). Moscow: Aspect Press.

Telia, V.N. (1996). Russian Phraseology. Semantic, Pragmatic and Linguoculturological Aspects. Moscow: Languages of Russian Culture.

Ter-Minasova, S.G. (2000). Language and Intercultural Communication: Study guide (pp. 624). Moscow: Slovo.

Tkhorik, V.I., \& Fanian, N.Yu. (2006). Cultural Linguistics and Intercultural Communication. Study Guide (pp. 260, Second edition). Moscow: GIS.

Ufimtseva, N.V. (1996 Additional edition in 2000). Russians: Experience of One More Self-cognition. Ethnocultural Specificity of Linguistic Consciousness (P. 139 - 163.). Moscow: Institute of linguistics.

Fatkullina, F.G. (2014). Phraseological View of the World: Basic Content and Characteristics. Modern Problems of Science and Education, 3; Retrieved 26.05.2014 from: http://www.science-education.ru/117-13230

Fatkullina, F.G. (2015). Typology of Concepts in Modern Linguistics. Pedagogical Journal of Bashkortostan, 1(15), 239-243.

Khairullina, R.Kh. (2005). Linguistics of International Communications: Series of Lectures (pp. 138). Ufa: Publishing House of the Bashkir State Pedagogic University.

Noskova, E.V., Romanova, I.M. (2014) Development of methodology to assess the effect of cross-cultural differences in the consumer behavior. Asian Social Science; Vol. 10, No. 24; P.248-256

Chernenko, L.O. (1997). Abstract Name and System of Notions of the Linguistic Identity. Language, Consciousness, Communication, 1, $50-51$.

Shmelev, A.D. (2002). Linguistic View of the World (Materials for the Dictionary). Moscow: Languages of Slavic Culture.

Shubart, V. (1997). Europe and Soul of the East. Moscow: Russian Idea. 